\title{
Xylene Induces Oxidative Stress and Mitochondria Damage in Isolated Human Lymphocytes
}

\author{
Ahmad Salimi', Behnaz Shoja Talatappe ${ }^{2}$ and Jalal Pourahmad ${ }^{2}$ \\ ${ }^{1}$ Department of Pharmacology and Toxicology, School of Pharmacy, Ardabil University of Medical Science, Ardabil, Iran \\ ${ }^{2}$ Department of Pharmacology and Toxicology, Faculty of Pharmacy, Shahid Beheshti University of Medical Sciences, Tehran, Iran
}

\begin{abstract}
Xylene is a cyclic hydrocarbon and an environmental pollutant. It is also used in medical technology, paints, dyes, polishes and in many industries as a solvent; therefore, an understanding of the interaction between xylene and human lymphocytes is of significant interest. Biochemical assessment was used to demonstrate that exposure of lymphocytes to xylene induces cytotoxicity (at $6 \mathrm{hr}$ ), generates intracellular reactive oxygen species, collapse of mitochondrial membrane potential, lysosomal injury, lipid peroxidation and depletion of glutathione (at $3 \mathrm{hr}$ ). The findings show that xylene triggers oxidative stress and organelle damage in lymphocytes. The results of our study suggest that the use of antioxidant, mitochondrial and lysosomal protective agents can be helpful for individuals subject to chronic exposure to xylene.
\end{abstract}

Key words: Xylene, Lymphocyte, Cytotoxicity, Mitochondrial damage, Oxidative stress

\section{INTRODUCTION}

Xylene is a cyclic hydrocarbon and an environmental pollutant, which is known by names such as dimethyl benzene and xylol (1). It is primarily used as a solvent in the printing, rubber, cleaning agent, paint thinner, varnish, synthetic fiber and leather industries. Contact with xylene occurs through the eyes and skin, orally and by inhalation. Occupations in which humans are exposed to xylene include histopathology laboratories, leather and rubber industries, petrochemicals and steel manufacturing (2-4).

Xylene has lipophilic properties. It is rapidly absorbed through all routes of exposure and quickly distributed throughout the body $(2,5)$. Studies have shown that chronic occupational exposure to xylene is associated with a variety of hematological effects (6). Decreased white blood cell counts were observed in two women with chronic occupational exposure to xylene $(7,8)$. Langman et al. found that chronic

Correspondence to: Jalal Pourahmad, Toxicology and Pharmacology Faculty of Pharmacy, Shahid Beheshti University of Medical Sciences, P. O. Box: 14155-6153, Tehran, Iran

E-mail: j.pourahmadjaktaji@utoronto.ca

This is an Open-Access article distributed under the terms of the Creative Commons Attribution Non-Commercial License (http:// creativecommons.org/licenses/by-nc/3.0) which permits unrestricted non-commercial use, distribution, and reproduction in any medium, provided the original work is properly cited. exposure to xylene is associated with thrombocytopenia, leukopenia and anemia. Occupational exposure to xylene significantly diminishes the percentage of lymphocytes in the peripheral blood $(2,9)$. Studies have reported that children whose parents are exposed to xylene in the workplace are at high risk for leukemia, although the females generally showed normal blood parameters (10). The current study was designed to identify the cellular effects of xylene on lymphocytes in light of the findings of previous studies regarding the probability of decreased white blood cell counts in humans following exposure to xylene and the compound effect of ameliorating immune system activity against viral infection.

\section{MATERIALS AND METHODS}

Blood samples. All blood samples $(\mathrm{n}=10)$ were acquired from Massoud Laboratory and approved by the Blood Administration Center of Tehran province in Iran. The studies were performed at the Faculty of Pharmacy at Shahid Beheshti University of Medical Sciences (Tehran, Iran) under the guidance of an expert physician. This study was approved by the Shahid Beheshti University of Medical Sciences research ethics committee and all participants signed informed consent forms (11).

Lymphocytes isolation. Lymphocytes were collected from healthy individuals who were 25 to 35 years of age. 
Blood was obtained from 10 healthy, non-smoking volunteers who showed no signs of infection at the time the blood samples were collected. Lymphocytes were isolated using Ficoll-Paque Plus (GE, PA, USA) by centrifugation at $2,500 \mathrm{~g}$ for $20 \mathrm{~min}$ at $4^{\circ} \mathrm{C}$. The lymphocytes were collected, suspended in erythrocyte lysis buffer $\left(150 \mathrm{mM} \mathrm{NH}_{4} \mathrm{Cl}\right.$, $10 \mathrm{mM} \mathrm{NaHCO} 3,1 \mathrm{mM}$ EDTA, $\mathrm{pH}$ 7.4) and incubated for 5 min at $37^{\circ} \mathrm{C}$. PBS was added immediately and the cells were centrifuged at $1,500 \mathrm{~g}$ for $10 \mathrm{~min}$ at $4^{\circ} \mathrm{C}$. The supernatant was decanted and the cells were washed twice with PBS at 2,000 g for $7 \mathrm{~min}$. The cells then were resuspended in RPMI1640 medium with L-glutamine and 10\% FBS. The final lymphocytes count used in the experiments was $1 \times 10^{6}$ cells $/ \mathrm{mL}$. The viability of the lymphocytes was over $95 \%$ (12).

Lymphocyte treatment. Commercial or mixed xylene usually contains $40 \%$ to $65 \%$ m-xylene and up to $20 \%$ each of o-xylene, p-xylene and ethylbenzene. The mixed xylene was first dissolved in $0.05 \%$ DMSO. The concentration of DMSO used in the experiments was non-toxic for lymphocytes as analyzed by cell viability and other parameters. The change in the untreated lymphocytes (negative controls) was $100 \%$. The final concentration of the xylene used in the experiments was 50 to $2,000 \mathrm{ng} / \mathrm{L}$. The cells were incubated in xylene for $6 \mathrm{hr}$ to determine cell viability and oxidative stress mechanistic parameters within $3 \mathrm{hr}$ of incubation. Incubation was carried out at $37^{\circ} \mathrm{C}$ in $5 \% \mathrm{CO}_{2}$ atmosphere (11).

Cell viability. Cell viability was assessed by MTT assay as described by Mosmann (13). In brief, lymphocytes $(1 \times$ $10^{4}$ cells/well) were incubated in 96-well plates with and without xylene for $6 \mathrm{hr}$ in a final volume of $10 \mu \mathrm{L}$. At the end of treatment, $25 \mu \mathrm{L}$ of MTT ( $5 \mathrm{mg} / \mathrm{mL}$ in RPMI) was added to each well and incubated for an additional $1 \mathrm{hr}$ at $37^{\circ} \mathrm{C}$. The purple-blue MTT formazan precipitate was dissolved in $100 \mu \mathrm{L}$ of DMSO and absorbance was measured at $570 \mathrm{~nm}$ with an ELISA reader. Each concentration was tested in three different experimental runs with three replicates per sample (12).

Reactive oxygen species assay. Reactive oxygen species (ROS) formation was measured at 1, 2 and $3 \mathrm{hr}$ by DCFH-DA staining. In brief, $950 \mu \mathrm{L}$ of cell suspension plus $50 \mu \mathrm{L}$ of a specific concentration of xylene were incubated at $37^{\circ} \mathrm{C}$ in $5 \% \mathrm{CO}_{2}$ atmosphere in 24 plates. At the end of incubation, the cell wells were suspended and $300 \mu \mathrm{L}$ was removed from each group. The removed cells were washed twice with PBS at 1,000 rpm for $5 \mathrm{~min}$. After washing, the cells were resuspended in $300 \mu \mathrm{L}$ of PBS containing 1.6 $\mu \mathrm{M}$ DCFH-DA and incubated for $15 \mathrm{~min}$. Next, $100 \mu \mathrm{L}$ of cells were diluted with deionized water in a cuvette and the fluorescence intensity of the DCF was measured using a
Shimadzu RF5000U fluorescence spectrophotometer. The excitation and emission wavelengths were 500 and $520 \mathrm{~nm}$, respectively (14).

Mitochondrial membrane potential assay. Mitochondrial membrane potential (MMP) collapse was measured at 1,2 and $3 \mathrm{hr}$ by rhodamine 123 staining. MMP assay is similar to measurement of ROS except that, after washing, the removed cells were resuspended in $300 \mu \mathrm{L}$ of PBS containing $1.5 \mu \mathrm{M}$ rhodamine 123 and incubated for $15 \mathrm{~min}$. Next, $100 \mu \mathrm{L}$ of cells were diluted with deionized water in a cuvette and the fluorescence intensity of the rhodamine 123 was measured using a Shimadzu RF5000U fluorescence spectrophotometer. The excitation and emission wavelengths were 490 and $520 \mathrm{~nm}$, respectively $(14,15)$.

Lysosomal membrane integrity assay. Lysosomal membrane integrity was measured after 1,2 and $3 \mathrm{hr}$ by acridine orange staining. Lysosomal membrane integrity assay is similar to measurement of ROS except that, after washing the removed cells, they were resuspended in $300 \mu \mathrm{L}$ of PBS containing $5 \mu \mathrm{M}$ of acridine orange and incubated for 15 min. Next, $100 \mu \mathrm{L}$ of cells were diluted with deionized water in a cuvette and the fluorescence intensity of the acridine orange was measured using a Shimadzu RF5000U fluorescence spectrophotometer. The excitation and emission wavelengths were 495 and $530 \mathrm{~nm}$, respectively (14).

Lipid peroxidation assay. Lipid peroxidation was measured after $3 \mathrm{hr}$ of exposure using the thiobarbituric acid reactive substances (TBARS) method. Briefly, $950 \mu \mathrm{L}$ of cell suspension plus $50 \mu \mathrm{L}$ of a specific concentration of xylene were incubated at $37^{\circ} \mathrm{C}$ in $5 \% \mathrm{CO}_{2}$ atmosphere in 24 plates. After exposure, $750 \mu \mathrm{L}$ of the exposed cells were combined with $250 \mu \mathrm{L}$ of $70 \%$ trichloroacetic acid (TCA) and $1 \mathrm{~mL}$ of distilled water was added. After $20 \mathrm{~min}, 1 \mathrm{~mL}$ of $0.8 \%$ thiobarbituric acid (TBA) was added. The mixture was placed in a boiling water bath for $20 \mathrm{~min}$ and then centrifuged at 13,000 rpm for $10 \mathrm{~min}$. The amount of TBARS formed during the decomposition of lipid hydroperoxides was determined by following the absorbance at $532 \mathrm{~nm}$ $(14,16)$.

GSH and GSSG. Reduced glutathione (GSH) and oxidized glutathione (GSSG) were determined according to the spectrofluorometric method. Each sample was measured in quartz cuvettes using a fluorimeter set at $350 \mathrm{~nm}$ of excitation and a $420 \mathrm{~nm}$ emission wavelength (14).

Statistical analysis. The results are presented as mean $\pm \mathrm{SD}$. The assays were performed in triplicate and the mean was used for statistical analysis. Statistical significance was determined using one-way and two-way ANOVA, followed 
by the post hoc Tukey and Bonferroni tests, respectively. Statistical significance was set at $p<0.05$.

\section{RESULTS}

Cell viability. The results showed that xylene significantly reduced the viability of lymphocytes after $6 \mathrm{hr}$ of incubation at concentrations of 1,000 to 2,000 ng/L. Fig. 1 shows xylene-induced cytotoxicity ( $28 \%$ and $38 \%)$ in the treated lymphocytes at 1,000 and $2,000 \mathrm{ng} / \mathrm{L}$, respectively.

ROS measurement. The results of ROS measurement showed that the amount of reactive oxygen radical formation after exposure to xylene increased significantly at concentrations of 500 2,000 ng/L after 1, 2 and $3 \mathrm{hr}$. Fig. 2A shows that Butylated hydroxytoluene (BHT) as an antioxidant significantly reduced xylene-induced blood lymphocyte ROS formation. $\mathrm{H}_{2} \mathrm{O}_{2}$ was used as a positive control for assessment of ROS formation. The effects of BHT, chloroquine and cyclosporine A (Cs.A) on the lymphocytes were separately tested (data not shown).

Malondialdehyde measurement. Fig. 2B showed that a significant amount of TBARS formed only when human blood lymphocytes were incubated in xylene at a concentration of 2,000 ng/L. Xylene-induced TBARS formation was prevented by ROS scavenging ( $50 \mu \mathrm{M}$ BHT), MPT pore sealing agent $(5 \mu \mathrm{M}$ Cs.A) and chloroquine, a lysosomotropic agent which inhibits a Fenton-type reaction. The effects of BHT, chloroquine and Cs.A on lipid peroxidation were separately tested (data not shown).

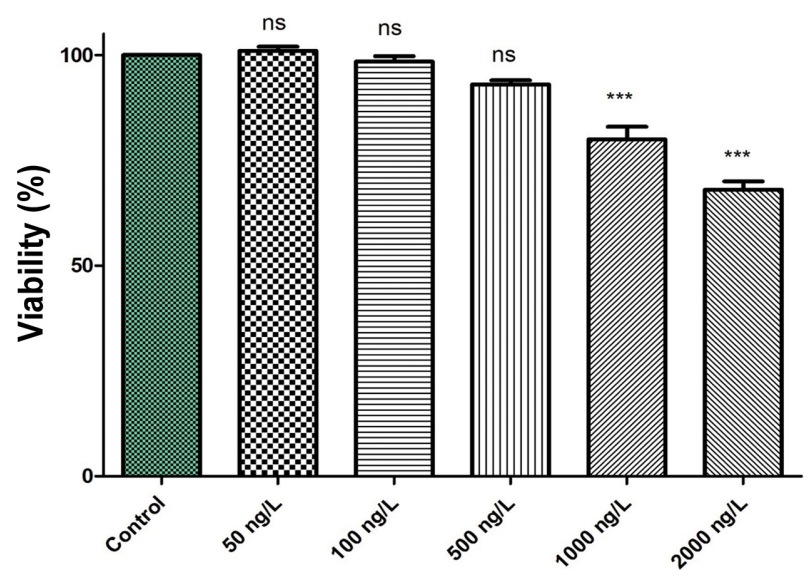

Fig. 1. Cell viability of lymphocytes from healthy donors seeded at $1 \times 10^{4}$ cells/well on 96-well plates, exposed to $50 \sim 2,000 \mathrm{ng} / \mathrm{L}$ xylene and then incubated for $6 \mathrm{hr}$. Absorbance representing the viability of the lymphocytes was determined by ELISA at $570 \mathrm{~nm}$. Data presented as mean \pm SD. The significance level was $p<0.05(\mathrm{n}=5)$. ${ }^{* * *}$ Denotes difference in comparison with untreated control $(p<0.001)$. NS: Non-significant in comparison with untreated control.
MMP assay. The results showed that xylene at all time intervals (1,2 and $3 \mathrm{hr})$ at concentrations of 500 and 2,000 $\mathrm{ng} / \mathrm{L}$ significantly decreased MMP in the blood lymphocytes. Concurrent use of an antioxidant (BHT), lysosomal Fenton reaction inhibitor (chloroquine) and MPT poresealing agent (Cs.A) with xylene $(1 \mu \mathrm{M})$ de- creased mitochondrial damage and inhibited MMP collapse. $\mathrm{Ca}^{+2}$ was used as a positive control for assessment of MMP collapse (Fig. 3). The effects of BHT, chloroquine and cyclosporine A on the MMP assay were separately tested (data not shown).
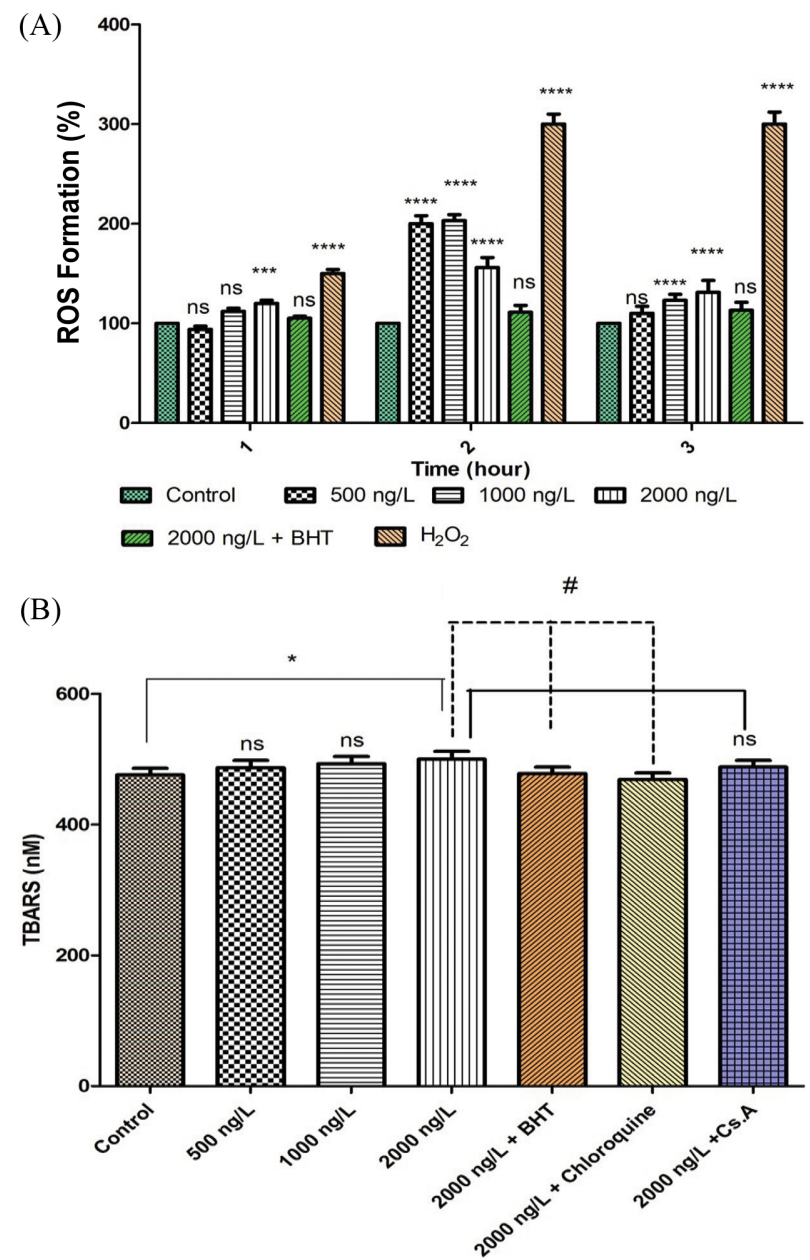

Fig. 2. Treated lymphocytes: (A) ROS formation; (B) lipid peroxidation. ROS formation was measured fluorometrically using DCF-DA. Lymphocytes $\left(10^{6}\right.$ cells $\left./ \mathrm{mL}\right)$ were incubated in RPMI 1640 at $37^{\circ} \mathrm{C}$ for $3 \mathrm{hr}$ following addition of xylene. TBARS formation is expressed as $\mathrm{nM}$. Values are expressed as mean $\pm \mathrm{SD}$ of three separate experiments $(n=5)$. *Significant difference in comparison with untreated control $(p<0.05)$. ${ }^{* *}$ Significant difference in comparison with untreated control $(p<0.001) .{ }^{* * *}$ Significant difference in comparison with untreated control $(p<$ .001). "Significant difference in comparison with xylene-treated lymphocytes $(2,000 \mathrm{ng} / \mathrm{L})$ and preventive agents (BHT, chloroquine and Cs.A) $(p<0.05)$. 


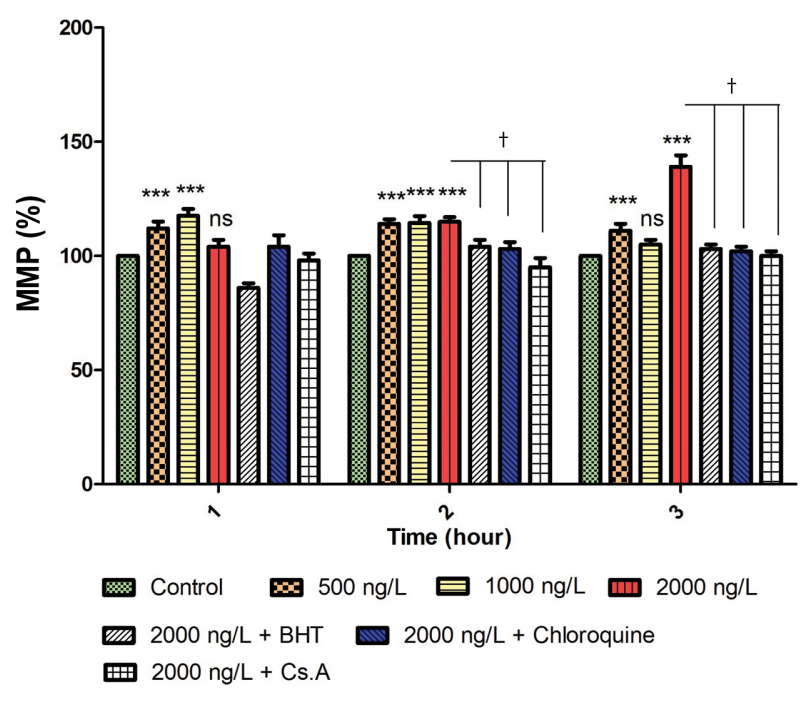

Fig. 3. MMP declines in xylene-treated lymphocytes compared to those of untreated control. MMP collapse was measured by rhodamine 123. Cs.A and BHT inhibited the decline of MMP in lymphocytes exposed to $2,000 \mathrm{ng} / \mathrm{L}$ of xylene $(p<0.001)$. Values represented as percentage of MMP decline $(n=3)$. ${ }^{* * *}$ Significant difference in comparison with untreated control $(p<0.001)$. ${ }^{\dagger}$ Denotes significant difference in comparison with xylenetreated lymphocytes $(p<0.05)$.

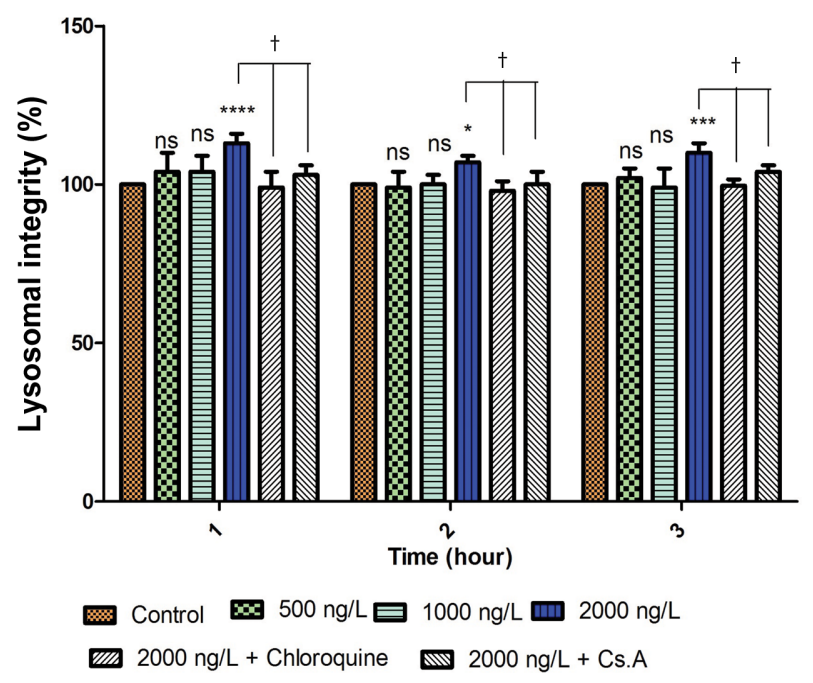

Fig. 4. Lymphocytes $\left(10^{6}\right.$ cells $\left./ \mathrm{mL}\right)$ incubated in RPMI 1640 at $37^{\circ} \mathrm{C}$. Lysosomal membrane damage was determined as the difference in redistribution of acridine orange from lysosomes into cytosol between the treated lymphocytes and untreated control lymphocytes. Results are shown as percentage of lysosomal membrane leakiness in all treated (test) lymphocyte groups. Values are expressed as mean \pm SD of three separate experiments $(n=5)$. The significant difference in comparison with the control lymphocytes was $p<0.05$. ${ }^{*}$ Significant difference in comparison with untreated control $(p<0.001)$. ${ }^{* * *}$ Denotes significant difference in comparison with xylene-treated lymphocytes ( $p<$ $0.001)$. ${ }^{\dagger}$ Denotes significant difference $(p<0.05)$ in comparison with lymphocytes treated with $2,000 \mathrm{ng} / \mathrm{L}$ of xylene.
Lysosomal membrane leakiness assay. The results showed that the highest concentration of xylene $(2,000 \mathrm{ng} / \mathrm{L})$ caused lysosomal membrane damage at 1,2 and $3 \mathrm{hr}$. Concurrent use of an antioxidant (BHT), lysosomal Fenton reaction inhibitor (chloroquine) and MPT pore-sealing agents (Cs.A, carnitine) with 2,000 ng/L of xylene prevented lysosomal damage and rupture of the lysosomal membrane (Fig. 4). The effects of BHT, chloroquine and Cs.A on the lysosomal membrane integrity were separately tested (data not shown).

GSH and GSSG measurement. Fig. 5 shows that incubation of lymphocytes in xylene at concentrations of
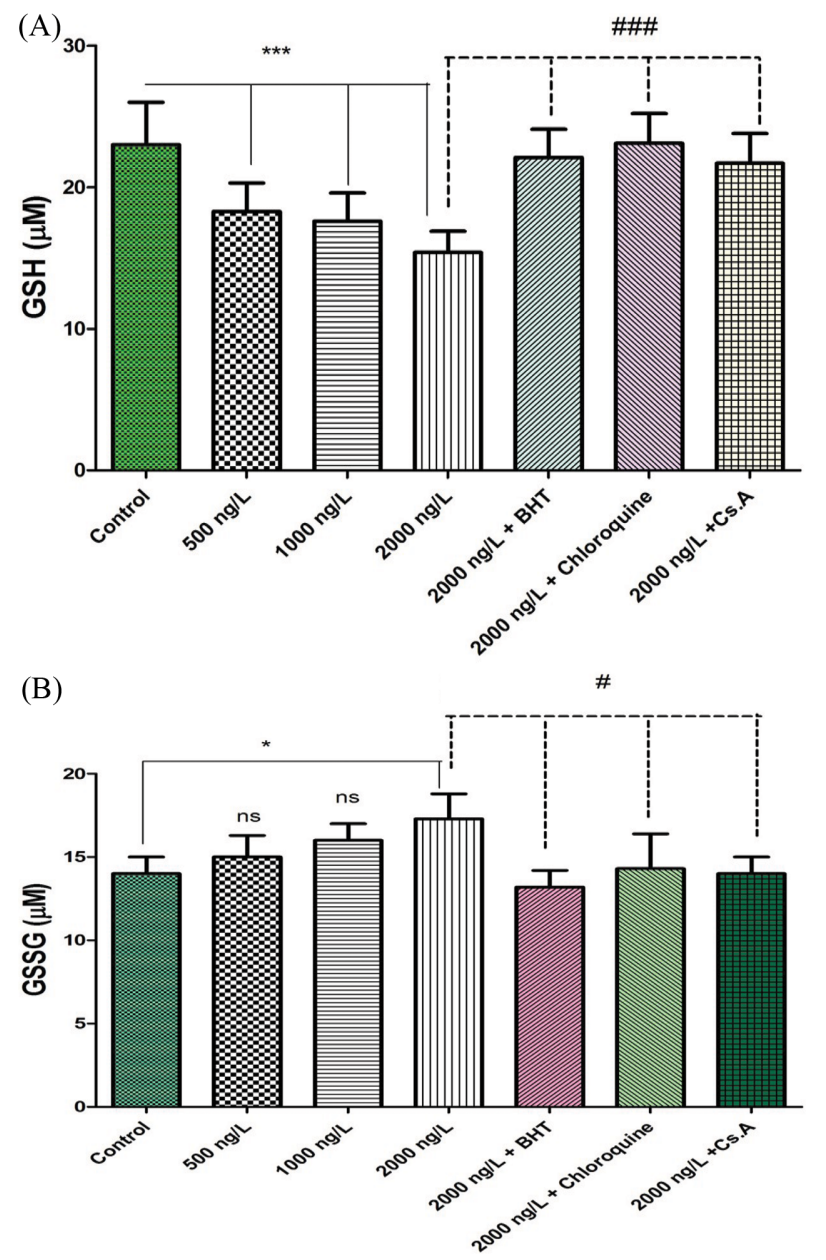

Fig. 5. Lymphocytes $\left(10^{6}\right.$ cells $\left./ \mathrm{mL}\right)$ incubated in RPMI 1640 at $37^{\circ} \mathrm{C}$ for $3 \mathrm{hr}$ following the addition of xylene. Fluorometrically determined: (A) intracellular GSH and (B) extra cellular GSSG. Values are expressed as mean $\pm S D$ of three separate experiments $(n=5)$. *Significant difference in comparison with untreated control $(p<0.05)$. ${ }^{* *}$ Denotes significant difference in comparison with untreated control $(p<0.001)$. "Denotes significant difference in comparison with xylene-treated lymphocytes and preventive agent $(p<0.05)$. \#\#\# Significant difference in comparison with $2,000 \mathrm{ng} / \mathrm{L}(p<0.001)$. 
$500 \sim 2,000 \mathrm{ng} / \mathrm{L}$ induced rapid lymphocyte intracellular GSH depletion (Fig. 5B). Most of the xylene-induced GSH depletion can be attributed to the expulsion of GSSG (Fig. 5B). Again, addition of an antioxidant (BHT), MPT poresealing agents (Cs.A and carnitine) and a lysosomotropic agent (chloroquine) significantly prevented a decrease in xylene-induced intracellular GSH and an increase in extracellular GSSG. None of these reagents produced a significant effect on lymphocyte GSH/GSSG status at the concentrations used (data not shown).

\section{DISCUSSION}

Decreased lymphocyte and serum complements were detected in workers who had been heavily exposed to xylene (8). Studies reveal adverse effects such as a decrease in the weight of the thymus and spleen in rats exposed to 2,000 $\mathrm{mg} / \mathrm{kg}$ of xylene daily (1). The results of the current study showed that xylene is toxic to human lymphocytes at 1,000 and 2,000 $\mathrm{ng} / \mathrm{L}$ after $6 \mathrm{hr}$ of exposure. Studies on humans and animals have shown that xylene is well-absorbed by inhalation and oral routes. In the blood, it is primarily bound to serum proteins and accumulates in adipose tissue (17). Xylene is very soluble in blood and therefore absorbed easily into systemic circulation after exposure. This means that it is likely to attain such high concentrations after chronic exposure (18). Interestingly, the toxic concentrations obtained in the current results were similar to the human exposure levels found by Perbellini et al (19).

Studies have found that the toxicity of many organic compounds appear to relate to the induction of ROS through systemic elevation of the normal cellular rate of oxygen radical generation (20-22). Studies have revealed that ROS are generated during metabolism of xylene (23). It was also recently reported that 0 -xylene can induce toxicity and apoptosis individually in Drosophila melanogaster and human leukemia cells by increasing ROS production $(20,23)$. In the present study, ROS production was altered in cells treated with xylene.

Previous investigations have shown that xylene is a more effective uncoupling agent and more effective in depleting ATP (24). Xylene is an aromatic hydrocarbon without proton releasing groups; therefore, rather than a protonophoretic mechanism, it binds to membrane hydrophobic sites such as proteins, an event which enhances its flux and/or interaction with the mitochondrial membrane targets (24). Revilla et al. found that xylene was capable of eliciting significant mitochondrial swelling in apparent association with increased ROS generation (24). The current results indicate that at the concentrations used, xylene could induce MMP collapse and increase ROS generation. The latter was inhibited by BHT as an antioxidant agent, which reflects the role of ROS formation in mitochondrial damage.

Hydrogen peroxide is mainly produced by the mitochon- dria and diffuses into lysosomes in abnormal amounts. Because many lysosomes are rich in redox-active $\mathrm{Fe}^{2+} / \mathrm{Fe}^{3+}$ due to degradation of iron-containing macromolecules, Fenton-type reactions then take place and result in lysosomal membrane rupture with the release of powerful lytic enzymes (25). The results of the current study showed that the use of antioxidant and MPT pore-sealing agents inhibited lysosomal damage.

In recent years, it has been suggested that lipid peroxidation plays an important role in toxicity induced by organic solvents (26). The results of the present study showed that xylene treatment of lymphocytes at $2,000 \mathrm{ng} / \mathrm{L}$ provoked potentiation of lipid peroxidation in the membranes of lymphocytes. It has also been suggested that xylene-induced lipid peroxidation may be a consequence of impairment of antioxidant defense systems such as glutathione and glutathione-related enzymes. The current study confirms these findings. It was shown that changes in the cellular defense system (decreased GSH content and increased GSSG) were associated with mitochondrial damage and ROS formation.

The current study reveals that xylene is toxic to human lymphocytes through ROS formation and mitochondrial and lysosomal damage that results in oxidative stress, depletion of GSH and cytotoxicity. Moreover, the current results suggest that the use of antioxidants can help protect individuals who are at risk of exposure to industrial solvents like xylene.

\section{CONFLICT OF INTEREST}

All authors declare that they have no conflict of interest.

\section{ACKNOWLEDGMENTS}

The results presented in this article were partly extracted from the thesis of Dr. Behnaz Shoja Talatappe (Pharm.D graduate of the Faculty of Pharmacy at Shahid Beheshti University of Medical Sciences) under the supervision of Prof. Jalal Pourahmad. The investigation was performed in the laboratory of Prof. J. Pourahmad at the Faculty of Pharmacy at Shahid Beheshti University of Medical Sciences in Tehran, Iran.

Received April 12, 2017; Revised May 20, 2017; Accepted May 31, 2017

\section{REFERENCES}

1. Niaz, K., Bahadar, H., Maqbool, F. and Abdollahi, M. (2015) A review of environmental and occupational exposure to xylene and its health concerns. EXCLI J., 14, 1167-1186.

2. Langman, J.M. (1994) Xylene: its toxicity, measurement of exposure levels, absorption, metabolism and clearance. Pathology, 26, 301-309.

3. Substances, A.f.T. and Registry, D. (2007) Toxicological pro- 
file for xylene, US Department of Health and Human Services, US Public Health Service, Agency for Toxic Substances and Disease Registry Atlanta, GA.

4. Šedivec, V. and Flek, J. (1976) Exposure test for xylenes. Int. Arch. Occup. Environ. Health, 37, 219-232.

5. Ogata, M., Takatsuka, Y. and Tomokuni, K. (1971) Excretion of hippuric acid and $\mathrm{m}$ - or p-methylhippuric acid in the urine of persons exposed to vapours of toluene and $\mathrm{m}$ - or $\mathrm{p}$-xylene in an exposure chamber and in workshops, with specific reference to repeated exposures. Br. J. Ind. Med., 28, 382-385.

6. Condle, L.W., Hill, J.R. and Borzelleca, J.F. (1988) Oral toxicology studies with xylene isomers and mixed xylenes. Drug Chem. Toxicol., 11, 329-354.

7. Moszczynsky, P. and Lisiewicz, J. (1984) Occupational exposure to benzene, toluene and xylene and the T lymphocyte functions. Haematologia (Budap), 17, 449-453.

8. Smolik, R., Grzybek-Hryncewicz, K., Lange, A. and Zatoński, W. (1973) Serum complement level in workers exposed to nebzene, toluene and xylene. Int. Arch. Arbeitsmed., 31, 243247.

9. Kim, K. (2015) Influences of environmental chemicals on atopic dermatitis. Toxicol. Res., 31, 89-96.

10. Lowengart, R.A., Peters, J.M., Cicioni, C., Buckley, J., Bernstein, L., Preston-Martin, S. and Rappaport, E. (1987) Childhood leukemia and parents' occupational and home exposures. J. Natl. Cancer Inst., 79, 39-46.

11. Salimi, A., Roudkenar, M.H., Sadeghi, L., Mohseni, A., Seydi, E., Pirahmadi, N. and Pourahmad, J. (2015) Ellagic acid, a polyphenolic compound, selectively induces ROS-mediated apoptosis in cancerous B-lymphocytes of CLL patients by directly targeting mitochondria. Redox Biol., 6, 461-471.

12. Salimi, A., Saharkhiz, M.P., Motallebi, A., Seydi, E., Mohseni, A.R., Nazemi, M. and Pourahmad, J. (2015) Standardized extract of the persian gulf sponge, axinella sinoxea selectively induces apoptosis through mitochondria in human chronic lymphocytic leukemia cells. J. Anal. Oncol., 4, 132-140.

13. Mosmann, T. (1983) Rapid colorimetric assay for cellular growth and survival: application to proliferation and cytotoxicity assays. J. Immunol. Methods, 65, 55-63.

14. Salimi, A., Vaghar-Moussavi, M., Seydi, E. and Pourahmad, J. (2016) Toxicity of methyl tertiary-butyl ether on human blood lymphocytes. Environ. Sci. Pollut. Res. Int., 23, 8556-8564.

15. Hosseini, M.-J., Naserzadeh, P., Salimi, A. and Pourahmad, J. (2013) Toxicity of cigarette smoke on isolated lung, heart, and brain mitochondria: induction of oxidative stress and cyto- chrome c release. Toxicol. Environ. Chem., 95, 1624-1637.

16. Seydi, E., Rajabi, M., Salimi, A. and Pourahmad, J. (2015) Involvement of mitochondrial-mediated caspase- 3 activation and lysosomal labilization in acrylamide-induced liver toxicity. Toxicol. Environ. Chem., 97, 563-575.

17. Astrand, I. (1982) Work load and uptake of solvents in tissues of man. Advances.

18. Astrand, I., Engström, J. and Övrum, P. (1978) Exposure to xylene and ethylbenzene. I. Uptake, distribution and elimination in man. Scand. J. Work Environ. Health, 4, 185-194.

19. Perbellini, L., Pasini, F., Romani, S., Princivalle, A. and Brugnone, F. (2002) Analysis of benzene, toluene, ethylbenzene and $\mathrm{m}$-xylene in biological samples from the general population. J. Chromatogr. B Analyt. Technol. Biomed. Life Sci., 778, 199-210.

20. Singh, M.P., Reddy, M.K., Mathur, N., Saxena, D. and Chowdhuri, D.K. (2009) Induction of hsp70, hsp60, hsp83 and hsp26 and oxidative stress markers in benzene, toluene and xylene exposed Drosophila melanogaster: role of ROS generation. Toxicol. Appl. Pharmacol., 235, 226-243.

21. Kalantari, H., Jalali, M., Jalali, A., Mahdavinia, M., Salimi, A., Juhasz, B., Tosaki, A. and Gesztelyi, R. (2011) Protective effect of Cassia fistula fruit extract against bromobenzeneinduced liver injury in mice. Hum. Exp. Toxicol., 30, 10391044.

22. Gueroui, M. and Kechrid, Z. (2016) Evaluation of some biochemical parameters and brain oxidative stress in experimental rats exposed chronically to silver nitrate and the protective role of vitamin E and selenium. Toxicol. Res., 32, 301-309.

23. Sarma, S.N., Kim, Y.J., Song, M. and Ryu, J.C. (2011) Induction of apoptosis in human leukemia cells through the production of reactive oxygen species and activation of HMOX1 and Noxa by benzene, toluene, and o-xylene. Toxicology, 280, 109-117.

24. Revilla, A.S., Pestana, C.R., Pardo-Andreu, G.L., Santos, A.C., Uyemura, S.A., Gonzales, M.E. and Curti, C. (2007) Potential toxicity of toluene and xylene evoked by mitochondrial uncoupling. Toxicol. In Vitro, 21, 782-788.

25. Kurz, T., Terman, A., Gustafsson, B. and Brunk, U.T. (2008) Lysosomes and oxidative stress in aging and apoptosis. Biochim. Biophys. Acta, 1780, 1291-1303.

26. Jajte, J., Stetkiewicz, J. and Wronska-Nofer, T. (2003) Combined exposure to $\mathrm{m}$-xylene and ethanol: oxidative stress in the rat liver. Int. J. Occup. Med. Environ. Health, 16, 345-350. 